\title{
A DIFERENCIAÇÃo DE PREÇOS ENTRE HOMENS E MULHERES EM ESTABELECIMENTOS COMERCIAIS: DIÁLOGO ENTRE A LIVRE INICIATIVA E A PROTEÇÃO DO DIREITO FUNDAMENTAL À IGUALDADE DE TRATAMENTO ENTRE HOMENS E MULHERES
}

\author{
DIFFERENTIATION OF PRICES BETWEEN MEN AND WOMEN IN SHOPS: A DIALOGUE BETWEEN \\ FREE ENTERPRISE AND THE PROTECTION OF THE FUNDAMENTAL RIGHT TO EQUAL \\ TREATMENT FOR MEN AND WOMEN
}

Francisco Dias de Oliveira Junior ${ }^{1}$ Fabio Campelo Conrado de Holanda ${ }^{2}$

\begin{abstract}
Resumo: $O$ presente trabalho tem como objetivo analisar a legalidade da diferenciação de preços entre homens e mulheres nas entradas de estabelecimentos comerciais ligados ao setor de lazer e entretenimento. Para isso serão observadas as diretrizes do princípio da livre iniciativa em face da intervenção estatal nas relações privadas, traçando um paralelo entre as duas. Em seguida far-se-á uma análise sobre a antidiscriminação e seus principais aspectos para com a figura da mulher. $O$ estudo utiliza como suporte metodológico a Nota Técnica emitida pela Secretaria do Direito do Consumidor do Ministério da Justiça no 2/2017 que emitiu parecer declarando a ilegalidade da prática e estabeleceu medidas punitivas para os estabelecimentos que permanecessem com a prática da diferenciação de preços. Por fim, buscar-se-á compreender se este costume é contrário aos preceitos do ordenamento jurídico brasileiro, explorando as principais vertentes que se desenrolaram após a emissão da nota, dentre eles o conflito entre os princípios constitucionais da livre iniciativa e da igualdade.
\end{abstract}

Palavras-chave: Diferenciação de preços. Princípio da igualdade. Livre iniciativa. Antidiscriminação.

\begin{abstract}
The present study aims to analyze the legality of price differentiation between men and women in the entrances of commercial establishments linked to the leisure and entertainment sector. For this, the guidelines of the principle of free initiative will be observed in the face of state intervention in private relations, drawing a parallel between the two. Next, a study will be carried out on antidiscrimination and its main aspects for the figure of the woman. The study uses as a methodological support the Technical Note issued by the Secretariat of Consumer Law of the Ministry of Justice that issued an opinion stating the illegality of the practice, including punitive measures for those establishments that remained with the practice of price differentiation. Finally, it will be sought to understand if this custom is contrary to the precepts of the Brazilian legal system, exploring the main strands of the concrete case that was established after the issuance of the technical note.
\end{abstract}

Keywords: Differentiation of prices. Principle of equality. Free Initiative. Anti-discrimination.

Recebido em 16 de setembro de 2018 Avaliado em 25 de setembro de 2018 (AVALIADOR A) Avaliado em 18 de dezembro de 2018 (AVALIADOR B)

Aceito em 18 de dezembro de 2018

\footnotetext{
Mestre em Direito pelo Centro Universitário 7 de Setembro (UNI7); Professor na Pós-graduação do Centro Universitário 7 de Setembro (UNI7) e na Unichristus; Avenida Almirante Maximiano da Fonseca, 1395, Engenheiro Luciano Cavalcante, 60811-020, Fortaleza, Ceará, Brasil; https://orcid.org/0000-0002-4618-7814; fdoj2009@hotmail.com

2 Doutor em Ciência Política pela Universidade Federal do Rio Grande do Sul; Professor no Curso de Mestrado em Direito Privado do Centro Universitário 7 de Setembro (UNI7); https://orcid.org/0000-0001-5125-5933; fabiodeholanda@yahoo.com.br
} 


\section{Introdução}

Em julho de 2017, a Secretaria Nacional do Consumidor, órgão vinculado ao Ministério da Justiça, através do Departamento de Proteção e Defesa do Consumidor, editou Nota Técnica de n. 2/2017/GAB-DPDC/DPDC/SENACON (BRASIL, 2017a) proibindo a cobrança diferenciada entre homens e mulheres no setor de lazer e entretenimento, obrigando bares, restaurantes e casas noturnas a vincularem-se a tal medida.

A diferenciação de preços entre homens e mulheres em estabelecimentos comerciais tornou-se prática consumerista habitual no Brasil. Assim regularmente essa temática ressurge ensejando debates jurídicos sobre a legalidade dessa prática e gerando insegurança para aqueles estabelecimentos que a buscam como marketing para atrair consumidores ou uma forma de se destacar da concorrência.

Durante todo o trabalho far-se-á a apreciação dessa Nota e a repercussão do seu desdobramento no mundo jurídico, de forma a estudar a interferência estatal ante a iniciativa privada e analisar se essa prática configura discriminação ou propicia o tratamento da mulher como objeto, diante da presença de um incentivo pecuniário para elas em estabelecimentos comerciais.

O trabalho busca, ao final, averiguar os efeitos jurídicos produzidos no âmbito consumerista para desta forma produzir uma análise reflexiva acerca da legalidade da diferenciação de preços entre homens e mulheres, para assim contribuir para a aplicação do entendimento explicitado.

Ao final, faz-se uma análise da colisão dos princípios da livre iniciativa e da igualdade de direito entre homens e mulheres, tendo como pano de fundo o cotejo deste caso concreto.

\section{A intervenção estatal em face do princípio da livre iniciativa}

A Nota Técnica em estudo, teve como fundamentação jurídica a decisão proferida em 6 de junho de 2017 pela $4^{a}$ Turma, do Juizado Especial de Brasília, em ação de conhecimento n. 071885221.2017.8.07.0016, na qual um consumidor se sentiu discriminado por uma produtora de eventos ao estipular ingressos de menor valor para as mulheres. $\bigcirc$ parecer daquele juízo ressaltou que a diferenciação de preço com base exclusivamente no gênero do consumidor não encontra respaldo no ordenamento jurídico pátrio (BRASIL, 2017b).

A interferência estatal justificou-se em virtude de que, segundo o julgador da $4^{\mathrm{a}}$ turma, o Código de Defesa do Consumidor foi bastante claro ao estabelecer o direito à 'igualdade nas contratações', e que no caso das mulheres a situação é delicada, já que uma prática repetida há tanto tempo pode traduzir uma falsa aparência de regularidade, de conformidade. 


\subsection{Breves considerações acerca da intervenção estatal na atividade econômica}

Raimundo Bezerra Falcão leciona que o Estado intervencionista nasce do receio, já encontrado em Maquiavel e Hobbes, de que "os apetites potestativos dos mais fortes terminassem por esmagar o patrimônio libertário individual dos mais fracos, o que era o caso da grande maioria." (FALCÃO, 2013, p. 29). Desse modo, cai por terra a célebre sustentação de que a melhor contribuição que cada um podia dá a ordem social seria sua contribuição de egoísmo pessoal.

Nessa toada, defende, acertadamente, Hobsbawn (2007, p. 105), que "o ideal de soberania do mercado não é um complemento à democracia, e sim uma alternativa a ela." Necessitando, portanto, que a soberania (liberdade) dos mercados seja constantemente limitada pela atuação do Estado como forma até mesmo de manter a democracia.

Afinal, defende-se aqui o argumento de Forgioni (2012, p. 170), com base na lição de Rudolf von Jhering, de que deixado livre no exercício de sua atividade, sem pressões competitivas ou sem controle estatal, a empresa tende a obter o maior lucro possível e, assim, explorar a coletividade.

Percebe-se que, ao longo do tempo, diversas foram as crises econômicas que acabaram por exigir do Estado não apenas o desempenho do seu papel de polícia, de protetor da propriedade privada e dos demais direitos individuais do cidadão, mas uma atuação mais enérgica e direcionada à prevenção ou correção das falhas de mercado, buscando reestabelecer o fluxo eficiente de alocação dos recursos pela sociedade (GRAU, 2001, p. 55).

Desse modo, a antiga visão ideológica do liberalismo econômico foi gradativamente abandonada. O Estado passa a desempenhar papel de destaque na economia nacional e corresponde a todo ato ou medida legal que restrinja, condiciona, ou tem por fim suprimir a iniciativa privada em determinada área visando o desenvolvimento nacional e a justiça social, assegurados os direitos e garantias individuais (GASPARINI, 1995, p. 430).

Segundo o artigo 173 da Constituição Federal, a intervenção do Estado no domínio econômico será autorizada quando necessária aos imperativos da segurança nacional ou diante da presença do relevante interesse coletivo, conforme definidos em lei. Denota-se que tais conceitos são vagos e conferem aos Poderes Legislativo e Judiciário ampla margem de discricionariedade dentro de seus campos de atuação.

Nessa direção, a segurança nacional mencionada no artigo refere-se basicamente à produção de bens e serviços indispensáveis ao regular funcionamento incluindo até mesmo ao satisfatório aparelhamento das forças armadas. No que tange ao relevante interesse, percebe-se que é conceito amplo e não diz respeito especificamente ao desempenho de atividade econômica estatal em face da ineficácia da iniciativa privada.

Dessa maneira apenas quando os interesses privados começam a se sobrepor aos interesses da coletividade a ponto de colocá-los em risco, é que o Estado fica autorizado a intervir diretamente 
na ordem econômica, demonstrando obviamente, que está em melhores condições que o particular para a consecução de seu fim (BASTOS, 1999, p. 255).

Cabe registrar que tanto a segurança nacional, quanto o relevante interesse coletivo, contidos no artigo, não são autoexecutáveis, necessitando da edição de legislação à que alude o artigo 173, parte final. $\bigcirc$ artigo 174 da Constituição refere-se à intervenção indireta do Estado na ordem econômica, de forma a atuar como agente normativo e regulador da atividade econômica, de tal sorte que o Estado exercerá, na forma da lei, as funções de fiscalização, incentivo e planejamento, sendo este determinante para o setor público e indicativo para o setor privado.

Silva (1996, p. 739) observa que:

Não se quer, com isso, dizer que a intervenção, nesses termos, dependa sempre de lei em cada caso específico. De fato, não se exige lei em cada caso para estimular e apoiar a iniciativa privada na organização e exploração da atividade econômica, como também não é mediante lei que se limitam atividades econômicas. Essas intervenções todas se realizam mediante ato administrativo, embora não possam se efetivar senão de acordo com previsão legal. As limitações sim, como ingerência disciplinadora, constituem formas de intervenção por via de regulamentação legal, mas o fomento nem sempre demanda lei, tal a implantação de infraestrutura, a concessão de financiamento por instituições oficiais, o apoio tecnológico.

O artigo 173, $\mathbb{S} 4^{\circ}$, da Constituição ressalta que a intervenção se dá nos casos de abuso do poder econômico que vise à dominação dos mercados, à eliminação da concorrência e ao aumento arbitrário de lucros, salvaguardando a livre iniciativa do art. 170. A autorização de descontos para as mulheres em estabelecimentos comerciais é prática comercial que reflete o momento econômico pelo qual o país atravessa, estimulando o consumo na medida em que atrai o público feminino.

Diante disso, a Associação Brasileira de Bares e Restaurantes seccional de São Paulo ajuizou Ação Civil Pública n. 5009720-21.2017.4.03.61 perante a 17ª Vara Cível de São Paulo (SÃO PAULO, 2018) sob a alegação de que a proibição da cobrança diferenciada de preços naqueles casos afetaria a livre iniciativa, prestigiada pelo arts. 1, inciso IV, e 170 da Constituição, tendo o pedido de liminar deferido.

O tópico seguinte abordará a livre iniciativa de maneira a examinar se seus fundamentos autorizam a cobrança diferenciada de preços entre homens e mulheres em estabelecimentos comerciais.

O juízo da citada $17^{a}$ Vara Cível de São Paulo que deferiu o pedido de liminar utilizou-se dentre outros fundamentos, o de que a interferência ocorreu de forma excessiva e desarrazoada ferindo o princípio da livre iniciativa, bem como princípios constitucionais da liberdade econômica e da segurança jurídica dos comerciantes, dentre outras dezenas de liberdades públicas estabelecidas pela Constituição.

Ademais, a livre iniciativa foi consagrada como fundamento do Estado Democrático de Direito ao lado da dignidade da pessoa humana no $\operatorname{artigo~} 1^{\circ}$ da Constituição, ressaltando o Juízo sobre 
a necessidade de estabelecer um equilíbrio entre tais princípios para conviverem harmoniosamente dentro de uma sociedade democrática.

Em razão disso, alegou-se que a proibição da prática consumerista, abusa do intervencionismo na iniciativa privada, criando embaraços à atividade econômica e que não se pode ocorrer uma imposição obrigatória do Estado ao agir dos estabelecimentos comerciais, como pretendeu o ato administrativo regulador através da Nota Técnica, devendo o Estado brasileiro interferir o mínimo possível na vida das pessoas.

\subsection{0 princípio da livre iniciativa: fundamentos jurídicos}

A Constituição estabeleceu, como fundamentos da ordem econômica, a valorização do trabalho humano e a livre iniciativa em seu artigo 170, caput, preocupando-se em colocar o Estado como ente subsidiário, deixando que os agentes de mercado tivessem a regência da economia nacional. Nesse sentido, também foi a livre iniciativa considerada como fundamento da república, ao lado da soberania, da cidadania, da dignidade da pessoa humana e do pluralismo político (art. 1 , IV).

Entende-se que o princípio da livre iniciativa não deve servir como escudo para que a classe empresarial exerça sua atividade com o escopo unicamente do lucro e realização pessoal. Dessa maneira Eros Grau entende que o artigo $1^{\circ}$, inciso IV da Constituição, enuncia o valor social do trabalho e o valor social da livre iniciativa, significando que, enquanto fundamento da República Federativa do Brasil, a livre iniciativa não é tomada como expressão individualista, mas no quanto se expressa de socialmente valioso (GRAU, 2003, p. 189).

Entretanto, sabe-se que a atuação empresarial é o alicerce principal da economia de um País, contribuindo na geração de empregos e no fortalecimento do poder do Estado, através do recolhimento de tributos e do alcance da autonomia produtiva. Para tanto, o princípio da livre iniciativa é de fundamental importância para garantir o crescimento econômico e está definido no Texto Constitucional como princípio fundamental do Estado Democrático de Direito.

Nessa direção, o princípio da livre iniciativa como assevera Eros Roberto Grau, é tradicionalmente identificado com a "liberdade de comércio e de indústria", "liberdade econômica ou liberdade de iniciativa econômica cujo titular é a empresa". Envolve o livre exercício de qualquer atividade econômica, liberdade de trabalho, ofício ou profissão, além da liberdade de contrato (GRAU, 2003, p. 184).

Na dicção de Comparato (1991, p. 18) o princípio da livre iniciativa comporta um duplo sentido: garante-se de um lado a livre criação ou fundação de empresas, ou seja, a liberdade de acesso ao mercado, mas protege-se também, de outro lado, a livre atuação das empresas já criadas, vale dizer, a liberdade de atuação e de permanência no mercado.

Conforme aduz Matias (2009, p. 93), é elemento fundamental do ideário liberal: a livre iniciativa, dela decorrendo a liberdade econômica, baseada na propriedade; e, a livre concorrência. 
Afirma que o princípio da livre iniciativa se tornou a base do sistema capitalista. Mas, a sua importância não deve ser superdimensionada, ensejando abusos. Pois, desde a sua formulação original, tal princípio não foi moldado em termos absolutos, posto que o seu exercício está subordinado às previsões legais (MATIAS, 2009, p. 93).

Não resta dúvida que, no ordenamento jurídico brasileiro, o princípio da livre iniciativa tem fundamento constitucional e infraconstitucional. Na Constituição Federal de 1988, referido princípio encontra guarida nos seguintes artigos: $1^{\circ}$, inciso IV e 170 . No artigo $1^{\circ}$, inciso IV, está estabelecido que a República Federativa do Brasil constitui-se em Estado Democrático de Direito e tem como fundamento, dentre outros, os valores sociais do trabalho e da livre iniciativa. Por seu turno, no artigo 170, está previsto que a ordem econômica tem como fundamento a valorização do trabalho humano e a livre iniciativa.

Salomão Filho (2003, p. 81), referindo-se à doutrina de Eros Roberto Grau, adverte que livre iniciativa não é sinônimo de liberdade econômica absoluta. O que ocorre é que o princípio da livre iniciativa, insculpido no caput do artigo 170 da CF/1988, nada mais é do que uma cláusula geral cujo conteúdo é preenchido pelos incisos do mesmo artigo. Esses incisos claramente definem a liberdade de iniciativa não como uma liberdade anárquica, porém social, e que pode, consequentemente, ser limitada.

A ordem econômica tem por finalidade assegurar a todos existência digna, conforme os ditames da justiça social (artigo 170, CF/1988). Desta forma, para ser considerada legítima, a liberdade de iniciativa deverá ser exercida com este fim, e não voltada simplesmente para o lucro ou para a realização pessoal do empresário.

Diante disso, pela própria redação do artigo 170 da Constituição, o princípio da livre iniciativa deve ser compreendido no contexto de uma sociedade preocupada com a justiça social e com o bem-estar coletivo, tornando-se legítimo quando destinado a assegurar a todos, dentro do sistema constitucional, a vida digna.

Como dito alhures, é baseando-se nesse princípio que se possibilita aos empreendedores a realização de inúmeras atividades, de diversas formas possíveis, organizando-se da maneira que melhor lhe satisfaça. Há doutrinadores que percebem a importância desse princípio e defendem uma posição mais liberal, como é o caso de Celso Ribeiro de Bastos, para o qual este princípio:

É uma manifestação dos direitos fundamentais e no rol daqueles devia estar incluída. De fato o homem não pode realizar-se plenamente enquanto não lhe for dado o direito de projetar-se através de uma realização transpessoal. Vale dizer, por meio da organização de outros homens com vistas à realização de um objetivo. Aqui a liberdade de iniciativa tem conotação econômica. Equivale ao direito que todos têm de lançarem-se ao mercado da produção de bens e serviços por sua conta e risco. Aliás, os autores reconhecem que a liberdade de iniciar a atividade econômica implica a de gestão e a de empresa. (BASTOS, 1999, p. 103).

Nessa esteira, argumentou-se ainda naquele Juízo que a normatividade do artigo 51, IV do CDC é condizente com a principiologia abarcante do artigo 170 "expressão de revelação da Justiça 
Social, proteção da dignidade humana, respeito à pessoa como centro de referência socioeconômica"; e qualquer relação de consumo que desrespeite o artigo 51, IV, estará desrespeitando o artigo 170 da Constituição.

Na medida em que a exploração da atividade econômica pela iniciativa privada submetese ao regime jurídico de direito privado, regendo-se em linhas gerais, por regras de direito civil de direito comercial, reservados à competência legislativa da União, nos termos do artigo 22, I, da CF.

Por fim, fundamentou o Juízo que o texto constitucional autoriza a intervenção estatal na economia por meio da regulamentação e regulação de setores econômicos, devendo se ajustar aos princípios da ordem econômica, nos termos do artigo 170 da Constituição Federal, desta forma, a faculdade atribuída ao Estado de criar normas de intervenção estatal na economia, não autoriza a violação do princípio da livre iniciativa.

Vale destacar que em períodos de recessão econômica, evita-se a interferência estatal na economia privada, de maneira que as próprias decisões judiciais buscam, através de uma visão econômica do Direito, desestimular tal interferência e desta forma contribuir para o crescimento econômico do país.

Ademais, o Supremo Tribunal Federal (STF), por meio do Recurso Extraordinário n. 349.686-7/PE, já assentou jurisprudência no sentido de que o princípio da livre iniciativa não pode ser invocado para afastar regras de regulamentação do mercado e de defesa do consumidor.

Basear-se-á o tópico seguinte nas diretrizes que fundamentam essa visão econômica do Direito, corroborando com a aceitação da cobrança diferenciada de preços entre homens e mulheres nos estabelecimentos comerciais do país.

\subsection{Percepção da interpretação econômica do Direito}

Segundo avaliação do Comitê de Datação de Ciclos Econômicos da Fundação Getúlio Vargas, a recessão de 2014 a 2016 foi a mais longa entre as nove datadas pelo órgão a partir de 1980, empatada com a de 1989 a 1992. A perda acumulada pelo PIB também foi a mais intensa da série histórica, mas muito similar com a queda de 8,5\% do PIB na recessão de 1981 a 1983 . O cálculo teve como base os dados das Contas Nacionais apuradas pelo Instituto Brasileiro de Geografia e Estatística (INSTITUTO BRASILEIRO DE ECONOMIA, 2015).

Cabe destacar que ao enfrentar uma crise econômica, é comum as decisões judiciais tenderem para uma visão mais econômica do Direito, de forma que problemas que antes seriam solucionados por outros critérios, passam a ser solucionados tendo como parâmetro essa análise econômica. Esta é basicamente o cerne da teoria proposta por Coase (2018).

Consoante às lições desse teórico a regulação jurídica deve reagir de forma diferente diante da presença de custos de transação ou na irrelevância desses. Na realidade, o teorema de Coase dividese em duas partes que devem ser vistas separadamente, as duas envolvendo o papel da regulação 
jurídica na presença de custos de transação consideráveis ou na irrelevância desses custos. $\bigcirc$ olhar do autor para o Direito merece destaque, pois é a base do chamado Law and Economics (COASE, 2018).

Nessa esteira, o Direito se relaciona à formação do ambiente econômico, ao atribuir direitos de propriedade e ao impor certos custos de transação. Explica o referido autor em sua obra que em se tratando de transações de mercado sem custos importaria apenas que os direitos das partes sejam bem definidos e as ações judiciais fáceis de prever (COASE, 2018).

Desse modo, quando as transações são muito dispendiosas elas dificultam uma modificação no regime de direitos estabelecido pelo ordenamento jurídico de forma que os tribunais influenciam de modo direto a atividade econômica. Percebem-se os benefícios de os tribunais terem uma boa compreensão das consequências econômicas de suas decisões.

Sendo assim, ao se tomar a decisão de interferir nas relações privadas de consumo, devemse levar em conta as consequências econômicas. Em razão disso, as determinações jurídicas devem analisar os efeitos negativos de certa atividade sobre terceiros em função também da normatividade econômica. Dessa forma, a interferência direta do Estado como pretendeu a Secretaria Nacional do Consumidor não se utilizou dessa análise em referida Nota Técnica.

\section{A mulher ante o instituto da antidiscriminação: uma análise à luz do princípio da igualdade}

Dentre os argumentos levantados que contribuem para a proibição da cobrança diferenciada de preços entre homens e mulheres está aquele que alude ser essa prática uma afronta ao princípio da igualdade e, por conseguinte há discriminação entre homens e mulheres. Diante disso, deve-se fazer uma análise da mulher à luz do instituto da antidiscriminação no que se refere ao conceito de discriminação direta e indireta.

Em agosto de 2017 a Advocacia Geral da União interpôs agravo de instrumento n. 5014964-92.2017.4.03.0000 requerendo a suspensão dos efeitos da liminar concedida pela $17^{a}$ Vara Cível de São Paulo junto ao Tribunal Regional Federal da $3^{a}$ Região, sob a alegação da ilegalidade da diferenciação de preços em estabelecimentos entre homens e mulheres.

Asseverou-se no agravo que o empresário-fornecedor não pode usar a mulher como "insumo" para a atividade econômica, servindo como "isca" para atrair clientes do sexo masculino para seu estabelecimento. Argumentou-se que admitir tal prática afronta, de per si, a dignidade das mulheres, ainda que de forma sutil, velada, na qual a intenção é oculta e pode travestir-se de pseudo homenagem, prestígio ou privilégio (OLIVEIRA JUNIOR, 2016).

Cumpre destacar que o conceito formal de igualdade embora seja uma concepção essencial para refutar discriminações injustificadas perante à lei, que se estabelecem a partir de privilégios, é insuficiente, pois restringe a igualdade ao formalismo, ao não só ignorar a desigualdade histórica das pessoas, mas pressupor uma igualdade inexistente entre elas (BRAGATO, 2017, p. 8). 
Em razão disso, a igualdade em sua concepção moderna veio à tona com o reconhecimento do Direito Internacional dos Direitos Humanos que certifica e celebra a diversidade de cada ser humano, de forma que a igualdade e a não discriminação são elementos fundamentais para garantia de tais direitos. Desta maneira, a concepção moderna de igualdade, embasada nos direitos fundamentais, abre precedentes para a exploração do conceito de discriminação, analisando as suas perspectivas jurídicas contemporâneas.

Roger Raupp Rios ao analisar o conceito moderno de discriminação, assevera que tendo por base as convenções internacionais sobre a eliminação de todas as formas de discriminação racial e contra a mulher, pode-se formular um conceito jurídico constitucional (RIOS, 2008, p. 19).

Esse teórico entende que discriminação é

qualquer distinção, exclusão, restrição ou preferência que tenha o propósito ou o efeito de anular ou prejudicar o reconhecimento, gozo ou exercício em pé de igualdade de direitos humanos e liberdades fundamentais nos campos econômico, social, cultural ou em qualquer campo da vida pública. (RIOS, 2008, p. 19).

Para o autor toda forma de prejudicar indivíduos ou grupos por meio de distinções ilegítimas no gozo e exercício de direitos, não abrangendo as hipóteses de diferenciação legítima, decorrentes da elaboração e aplicação de norma jurídica em face de situações desiguais, corresponde o que vem a ser o conceito jurídico constitucional de discriminação (RIOS, 2008, p. 19).

Ressalte-se ainda que a concepção das duas modalidades de discriminação em direta e indireta é aceita no direito internacional, mas encontra dificuldades na doutrina e jurisprudência pátria.

Nesse contexto elas estão ligadas as expressões a "propósito" e a "efeito" do conceito explicitado pelo autor, de forma que a primeira se refere às práticas intencionais e conscientes pertencendo à modalidade direta de discriminação, enquanto a segunda refere-se às realidades que se reproduzem ao longo do tempo por meio da manutenção de medidas aparentemente neutras, mas efetivamente discriminatórias pertencendo à modalidade indireta de discriminação.

Consoante ainda às lições de Roger Raupp Rios existe um tratamento igualitário e consequentemente a proibição da discriminação direta, entretanto, para ele alguns grupos populacionais podem ficar à margem de outros, tendo em vista a relação de desvantagem em que vivem. Nessa esteira, para a configuração da discriminação direta, é prescindível a existência da intencionalidade, ao menos em sua forma explícita (RIOS, 2008, p. 117).

Destaca-se que, dada a maior dificuldade em se constatar a discriminação indireta, o fundamento da proibição dessa modalidade insere-se, em um debate mais amplo que remete à compreensão da realidade social, política, histórica, cultural e econômica de determinada sociedade.

Segundo o entendimento de Bragato (2014, p. 12) as ações e leis têm como efeito a discriminação indireta, pois seguem o princípio da igualdade formal, ao determinar que a lei trate 
a todos de forma igual. De acordo com a autora através desse comportamento atuam para reforçar situações condenáveis, mesmo que não intencionais, de desigualdade e de preconceito que resultam na privação de direitos a indivíduos e grupos que não fazem parte da parcela dominante da sociedade.

Em razão disso a igualdade se concretiza diante da certificação de não discriminação, daí a importância da análise desse paralelismo entre os dois. Para tanto, necessária se faz a constatação da existência de grupos vulneráveis numa sociedade. Bragato (2014, p. 13) ao estudar vulnerabilidade esclarece que:

Quando a modernidade europeia assentou o fundamento da dignidade na racionalidade humana e construiu o conceito de raça e racismo, produziu-se, historicamente, a construção de um padrão de humanidade encarnado na figura do indivíduo masculino, branco, proprietário, ocidental, heterossexual e cristão. Como padrão unitário, superior e cientificamente orientado de comportamento, a racionalidade tornou-se um atributo culturalmente centrado (ou etnocêntrico) e, portanto, ausente em diversos exemplares da espécie humana, como é o caso das mulheres, dos estrangeiros, dos colonizados, dos negros, dos deficientes e assim por diante.

Nesse ínterim, acrescentou ainda a autora que negros, índios, mulheres, homossexuais, não cristãos e outros experimentam muito mais obstáculos no acesso a seus direitos humanos que indivíduos e grupos que se adequam aos padrões dominantes. Ou seja, para justificar que alguns não tinham seus direitos, foi necessário antes, afirmar que eles não eram seres humanos em sua integralidade (BRAGATO, 2014, p. 16).

Nessa direção, a maioria dos tratados e jurisprudência permite ou até mesmo exige que a situação de desvantagem de grupos vulneráveis ou desfavorecidos seja o objetivo das medidas de ação de afirmação desses grupos. Em virtude disso, nem toda distinção ou diferença de tratamento configura discriminação, este é o cerne do instituto da antidiscriminação.

Sendo assim, ao se aceitar que as mulheres fazem parte desse grupo vulnerável, somada a constatação que entre elas e os homens existe não uma igualdade formal, mas sim material, permite concluir que a diferenciação de preços entre homens e mulheres na entrada de determinados estabelecimentos comerciais, de maneira a conceder descontos para o público feminino, não configura discriminação direta nem indireta para com o grupo masculino.

Indaga-se em contrapartida se a concessão de descontos para as mulheres possibilita o tratamento da mulher como objeto, tendo em vista que tal prática consumerista teria como público alvo o masculino e não o público feminino em si. O próximo tópico buscará explicar a objetificação da mulher dentro da chamada teoria feminista do Direito. 


\subsection{Teoria feminista do Direito}

Registre-se que a menção ao feminismo tem por objetivo demonstrar que não se pode afirmar que há tratamento da mulher como objeto ante a estratégia de marketing para atrair o público masculino através da diferenciação de preços entre homens e mulheres na entrada de estabelecimentos comerciais, sem antes analisar a abordagem da teoria do feminismo do Direito.

Segundo Rios (2008, p. 48), parte das premissas básicas do movimento feminista, criticando a pretensa neutralidade do Direito como um processo neutro e universal de tomada de decisões do ponto de vista sexual, afirmando sua incapacidade de responder adequadamente à condição feminina e aos interesses, valores, ameaças e danos experimentados por mulheres.

Consoante às lições do referido autor, dentro dessa teoria destacam-se as principais correntes, dentre elas o feminismo liberal, feminismo culturalista, feminismo radical e feminismo pós-moderno. Para ele as feministas liberais defendem a superação das desigualdades experimentadas pelas mulheres mediante a igualdade de tratamento, relutando admitir medidas diferenciadas por nelas vislumbrar a presença de uma ideologia de superioridade masculina (RIOS, 2008, p. 49).

Nessa direção, trata-se de uma postura tipicamente antidiferenciadora, tanto que algumas feministas liberais são chamadas de "feministas simétricas", numa referência ao modo de aplicação da igualdade entre homens e mulheres. Tal corrente advoga, por exemplo, a identificação da gravidez a qualquer outra condição física que inabilite homens ao trabalho, à semelhança de qualquer doença, ao invés de uma capacidade única e positiva (RIOS, 2008, p. 49).

A principal crítica do autor a essa corrente de feministas, oralmente chamadas de "assimilacionistas", é porque ela implica a aceitação do modelo masculino como norma universal em face da qual a igualdade de tratamento será verificada e à qual as mulheres devem se conformar.

No que tange ao feminismo culturalista ilustrado pelo teórico, postula-se a existência de diferenças fundamentais entre homens e mulheres. Nessa esteira, ao fazer isso, estabelece-se que o tratamento igual destas duas realidades diversas só é possível através da aplicação de medidas diferenciadas e pressupõe uma aplicação assimétrica do princípio da igualdade, centrada na condição feminina diferenciada da masculina (RIOS, 2008, p. 49).

Essa corrente admite a assimetria como estratégia de antidiscriminação. $\bigcirc$ feminismo radical, por sua vez, sustenta que a desigualdade sexual no direito é resultado da sistemática subordinação social das mulheres, não simplesmente uma aplicação irracional e preconceituosa do princípio da igualdade (RIOS, 2008, p. 51).

Quando se questiona sobre a exposição da mulher como estratégia de marketing para atrair o público masculino nos estabelecimentos de lazer e entretenimento, deve-se perceber que a necessidade primeira de tais estabelecimentos é atrair o público feminino tendo como alvo o próprio público feminino, de tal forma que essa prática ocorre em vários outros setores da atividade consumerista como por exemplo academias voltadas exclusivamente para o público feminino. A 
mulher inclusive, como qualquer pessoa, tem a opção de escolha do lugar que pretende frequentar para o seu lazer, de tal forma que em se tratando de local que não lhe é conveniente, opta-se por não o frequentar.

Em outubro de 2017 o Coritiba Foot Ball Clube, em estratégia comercial semelhante, com o intuito de atrair o público feminino em uma partida de futebol, onde há maioria masculina, anunciou uma promoção para o jogo contra o Grêmio, às $19 \mathrm{~h}$ do domingo, dia 15 daquele mês, no estádio do Couto Pereira. Possibilitou na ocasião que crianças até 14 anos e mulheres teriam acesso gratuito ao duelo válido pela 28a rodada do Brasileirão (CORITIBA x GRÊMIO..., 2017).

Referida oferta promocional corrobora com o entendimento de que a diferenciação de preços entre homens e mulheres é prática consumerista e não tem relação com o ferimento à dignidade da mulher, relaciona-se, pois, com estratégia de mercado. Por fim, defender uma intervenção estatal para proibição dessa conduta é ferir os princípios da livre iniciativa e liberdade de comércio necessários à proteção do consumidor na defesa da concorrência.

\section{A colisão entre o princípio da livre iniciativa e da igualdade: uma análise do caso concreto}

No que se refere à colisão entre princípios constitucionais, na precisa lição de Robert Alexy os princípios instituem obrigações prima facie, na medida em que podem ser superados ou derrogados em função de outros princípios colidentes (ÁVILA, 2011, p. 44).

Para Ronald Dworkin, os princípios, ao contrário das regras, não determinam absolutamente a decisão, mas somente contém fundamentos, que devem ser julgados com outros fundamentos provenientes de outros princípios (ÁVILA, 2011, p. 51). Para ele, os princípios possuem uma dimensão de peso que se exterioriza na hipótese de colisão, caso em que o princípio com peso relativamente maior se sobrepõe ao outro, sem que este perca sua validade (ÁVILA, 2011, p. 51).

Logo, ocorrendo colisão entre princípios constitucionais, a ponderação é a consequência necessária, pois os princípios entram em conflito no plano concreto e a solução do conflito insere-se na problemática da aplicação.

Não há dúvidas de que no caso em tela - ou seja, do tratamento diferenciado entre homens e mulheres nas entradas em estabelecimentos comerciais - há uma colisão entre o princípio da livre iniciativa e da igualdade entre homens e mulheres. E neste caso, tanto a igualdade como a liberdade, representado pela livre iniciativa, devem ser vistas como multidimensionais dentro de seus amplos conteúdos. Assim, deve-se evitar a adoção de uma visão estreita e unifocal da igualdade ou da liberdade, de forma a que venham a ignorar outras considerações que esses valores exigem (SEN, 2011, p. 51).

Afirmara, certa vez, Charles Dickens que "não há nada que seja percebido e sentido tão precisamente quanto a injustiça." (SEN, 2011, p. 9). E, certamente, foi isso que foi percebido nesse 
fato concreto, qual seja, dos estabelecimentos comerciais concederem desconto ou até a gratuidade para a entrada de mulheres em estabelecimentos comerciais (baladas, festas, etc.). Tanto o foi, que tanto as mulheres, as beneficiadas diretas pela medida, quanto os homens, os possíveis prejudicados pela medida, em sua maioria, se pronunciaram contra tais medidas comerciais. ${ }^{3}$

Além do mais, na análise desse caso concreto não se pode olhar unidirecionalmente apenas para o direito, deve-se também analisar a questão moral relacionada à temática, pois "sem a presença do sentimento moral, torna-se a ordem jurídica altamente imperfeita e incerta." (JHERING, 2002). Desta forma, seria moral e ético conceder descontos as mulheres não extensíveis aos homens? Sobre que fundamento?

Para Francisco José Soares o liberalismo econômico (livre iniciativa), divorciado do solidarismo social (igualdade), aguça o espirito de competitividade e acentua o grau de excludência. E toda ideia ou instituição que exclui, gera sua própria fragilidade (SOARES, 2013, p. 113).

Conforme leciona este Autor, os gregos, que formularam os primeiros princípios da Filosofia do Direito, "erigiram a igualdade como um dos fundamentos primordiais da deontologia jurídica, assim como a homogeneidade social representa o apanágio maior da democracia política." (SOARES, 2013, p. 113).

Ademais, em nome do liberalismo econômico e da livre iniciativa não se pode permitir que as mulheres, que foram ao longo dos tempos, as grandes injustiçadas da História, continuem a carregar esse fardo da desigualdade, justamente em seus momentos de cultura e lazer. Afinal, parece que todas as instituições de uma cultura milenária parecem comprometidas com o mito da masculinidade (SOARES, 2013, p. 113).

A Constituição Federal adotou o princípio da livre iniciativa como alicerce da ordem econômica ao mesmo passo que alçou o princípio da isonomia como essencial para a garantia do fundamento da dignidade da pessoa humana.

Assim, não estabelecer limites ao princípio da livre iniciativa - o qual, preconiza uma liberdade de escolha e/ou ação econômica - pode resultar em óbices ou impedimento ao bem-estar econômico e social. Como, por exemplo, nos casos de concentração de poder de mercado e de seu exercício abusivo, decorrente, à priori, do exercício da liberdade decorrente do princípio da livre iniciativa.

\section{Conclusão}

Nos tópicos antecedentes analisou-se a legitimidade da diferenciação de preços entre homens e mulheres em estabelecimentos comerciais. Verificou-se que este é um assunto que perpassa

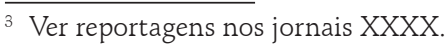


a simples apreciação de conceitos básicos de Direito do Consumidor, para isso buscou-se examinar a interferência estatal nas relações privadas ante o princípio da livre iniciativa.

Em seguida fez-se uma análise sobre o instituto da antidiscriminação e constatou-se que se pode afirmar que a prática consumerista em análise fere o princípio da igualdade entre o homem e a mulher tendo em vista que a compreensão mais geral do Direito deve reconhecer que estamos lidando com sociedades verdadeiramente plurais e desiguais, marcadas pela existência de grupos dominantes e de grupos minoritários.

Dessa maneira, a constatação da mulher como parte dos grupos vulneráveis reforça a noção de que determinadas categorias de pessoas encontram-se em situação de maior vulnerabilidade e assim justifica tratamentos diferenciados no sentido de facilitar o acesso aos direitos humanos.

O desenvolver do caso demonstrou que há uma tendência por parte do judiciário em desenvolver decisões voltadas para a interpretação econômica do Direito. Em virtude disso, há uma tendência no Direito em afastar a intervenção estatal das relações privadas em prol da liberdade econômica das relações consumeristas.

Por fim destacou-se que as discriminações que devem ser evitadas e combatidas são aquelas que humilham e afrontam a honra, de maneira que a conduta adotada pelos estabelecimentos comerciais demonstrou o exercício de uma prática consumerista, e não uma afronta aos direitos fundamentais.

\section{Referências}

ÁVILA, Humberto. Teoria dos princípios. 2. ed. São Paulo: Malheiros, 2011.

BASTOS, Celso Ribeiro. Curso de Direito administrativo. 3. ed. São Paulo: Saraiva, 1999.

BRAGATO, Fernanda Frizzo. Direitos humanos no segundo pós-guerra: entre as respostas racionalistas da modernidade e o desafio das vulnerabilidades. Revista de Informação Legislativa, ano 51, n. 204, out./dez. 2014. Disponível em: http://www.senado.leg.br. Acesso em: 10 out. 2017.

BRASIL. Ministério da Justiça e Segurança Pública. Nota técnica n. 2/2017/GAB-DPDC/DPDC/ SENACON. Processo n. 08012.001609/2017-25. 2017a. Disponível em: http://www.justica.gov.br/ news/diferenciacao-de-precos-em-funcao-de-genero-e-ilegal/nota-tecnica-2-2017.pdf/view. Acesso em: 5 ago. 2018.

BRASIL. Tribunal de Justiça do Distrito Federal. Processo n. 0718852-21.2017.8.07.0016. Relator: Arnaldo Correa Silva. Órgão Julgador: $4^{\circ}$ Juizado Especial Cível de Brasília. Jusbrasil, Brasília, DF, 29 set. 2017b. Disponível em: https://pje.tjdft.jus.br/consultapublica/ConsultaPublica/listView. seam. Acesso em: 15 ago. 2018.

COASE, Ronald. The Nature of the Firm: Origin. Disponível em: http://heinoline.com. Acesso em: 5 ago. 2018.

COMPARATO, Fábio Konder. Regime constitucional do controle de preços no mercado. Revista de Direito Público, n. 24, 1991. 
CORITIBA X GRÊMIO: crianças e mulheres terão entrada gratuita no Couto Pereira. Portal de Notícias G1, Curitiba, 12 out. 2017. Disponível em: https://globoesporte.globo.com/pr/futebol/times/ coritiba/noticia/coritiba-x-gremio-criancas-e-mulheres-terao-entrada-gratuita-no-couto-pereira. ghtml. Acesso em: 10 ago. 2018.

FALCÃO, Raimundo Bezerra. Direito econômico: teoria fundamental. São Paulo: Malheiros, 2013.

FORGIONI, Paula Andrea. A evolução do direto comercial brasileiro: da mercancia ao mercado. 2. ed. São Paulo: RT, 2012.

GASPARINI, Diógenes. Direito administrativo. 4. ed. São Paulo: Saraiva, 1995.

GRAU, Eros Roberto. A ordem econômica na Constituição de 1988. 8. ed. São Paulo: Malheiros, 2003.

GRAU, Eros Roberto. A ordem econômica na Constituição de 1988: interpretação e crítica. 6. ed. rev. e atual. São Paulo: Malheiros, 2001.

HOBSBAWN, Eric. Globalização, democracia e terrorismo. Tradução: José Viegas. São Paulo: Companhia das Letras, 2007.

INSTITUTO BRASILEIRO DE ECONOMIA. Comitê de Datação de Ciclos Econômicos Brasileiros. Rio de Janeiro, 4 ago. 2015. Disponível em: http://portalibre.fgv.br/lumis/portal/file/fileDownload. jsp?fileId=8A7C82C54DB5CA9F014EF8794F847120. Acesso em: 10 ago. 2018.

JHERING, Rudolf von. A finalidade do direito. São Paulo: Saraiva, 2002.

MATIAS, João Luís Nogueira. A função social da empresa e a composição de interesses na sociedade limitada. Orientadora: Paula Andrea Forgioni. 2009. 323 f. Tese (Doutorado em Direito Comercial) - Faculdade de Direito da Universidade de São Paulo, São Paulo, 2009.

OLIVEIRA JUNIOR, Francisco Dias. O preconceito sutil em face do constitucionalismo fraterno. Revista Themis, Tribunal de Justiça do Ceará, v. 14, n. 1, p. 173-201, 2016. Disponível em: http:// revistathemis.tjce.jus.br/index.php/THEMIS/article/view/534. Acesso em: 5 ago. 2018.

RIOS, Roger Raupp. Direito da antidiscriminação: discriminação direta, indireta e ações afirmativas. Porto Alegre: Livraria do Advogado, 2008.

SALOMÃO FILHO, Calixto. Direito concorrencial: as condutas. São Paulo: Malheiros Editores, 2003.

SÃO PAULO (Estado). Tribunal de Justiça de São Paulo. 17ª Vara Cível Federal de São Paulo. Ação Civil Pública (65) n. 5009720-21.2017.4.03.6100. Disponível em: https://www.jusbrasil.com.br/ diarios/documentos/483656979/andamento-do-processo-n-5009720-2120174036100-acao-civil-publica-02-08-2017-do-trf-3?ref=topic_feed. Acesso em: 6 ago. 2018.

SEN, Amartya. A ideia de justiça. Tradução: Denise Bottmann, Ricardo Doninelli Mendes. São Paulo: Companhia das Letras, 2011.

SILVA, José Afonso da. Curso de direito constitucional positivo. 11. ed. São Paulo: Saraiva, 1996.

SOARES, Francisco José. Justiça: eis a questão. Fortaleza: Expressão Gráfica e Editora, 2013. 
